\title{
Overlooked and underserved: Widowed fathers with dependent-age children
}

\author{
JUSTIN M. YOPP, PH.D., ${ }^{1}$ ELIZA M. PARK, M.D., ${ }^{1}$ TERESA EDWARDS, M.A., ${ }^{2}$ \\ ALLISON DEAL, M.SC., ${ }^{3}$ AND DONALD L. ROSENSTEIN, M.D. ${ }^{1,4}$ \\ ${ }^{1}$ Department of Psychiatry, University of North Carolina at Chapel Hill, Chapel Hill, North Carolina \\ ${ }^{2}$ H.W. Odum Institute for Research in Social Science, University of North Carolina at Chapel Hill, Chapel Hill, North \\ Carolina \\ ${ }^{3}$ Lineberger Comprehensive Cancer Center, University of North Carolina at Chapel Hill, Chapel Hill, North Carolina \\ ${ }^{4}$ Department of Medicine, University of North Carolina at Chapel Hill, Chapel Hill, North Carolina \\ (RECEIVED August 28, 2014; ACCEPTED October 1, 2014)
}

\begin{abstract}
Objective: Widowed fathers and their children are at heightened risk for poor coping and maladaptive psychosocial outcomes. This exploratory study is the first to explicitly examine the psychological characteristics of this population of fathers.

Method: Some 259 fathers (mean age $=46.81 ; 90 \%$ Caucasian) with dependent-age children and whose wives had died from cancer within the previous five years completed a web-based survey that consisted of demographic questions, the Center for Epidemiologic Studies Depression Scale (CES-D), the Texas Inventory of Grief-Revised (TRIG-R), the Psychological Adaptation Scale (PAS), the Kansas Parental Satisfaction Scale (KPSS), and items assessing perceived parental efficacy.

Results: Fathers were found to have elevated depressive $(\mathrm{CES}-\mathrm{D}$ mean $=22.6)$ and grief $($ TRIG $-\mathrm{R}$ mean $=70.3)$ symptomatology, low adaptation $($ PAS mean $=3.2)$, and high levels of stress related to their parenting role. They reported being satisfied with their parenting (KPSS mean $=15.8$ ) and having met their own parental expectations. Multivariate analyses revealed an association between father's age and depression $(p=<0.01)$, with younger fathers reporting greater depressive symptoms. Psychological adaptation was positively correlated with being in a romantic relationship $(p=0.02)$ and age of oldest child $(p=0.02)$.

Significance of results: The results of our exploratory study suggest that, while widowed fathers perceive themselves as meeting their parental responsibilities, it comes at a substantial psychological cost, with particularly high stress related to being a sole parent. These findings may help guide interventions for this neglected population and underscore the importance of developing targeted therapies and research protocols to address their needs.
\end{abstract}

KEYWORDS: Bereavement, Widower, Family, Father, Depression

\section{INTRODUCTION}

In families with children in the home, parental death is a traumatic event that can negatively affect the psychosocial trajectory of surviving family members and alter intrafamilial relationship dynamics. Children and adolescents who experience early parental

Address correspondence and reprint requests to: Justin M. Yopp, Department of Psychiatry, University of North Carolina at Chapel Hill, 170 Manning Drive, CB\# 7218, Chapel Hill, North Carolina 27599. E-mail: justin_yopp@med.unc.edu. loss are at greater risk for such negative outcomes as depression, anxiety, poor academic performance, and somatic complaints (Cerel et al., 2006; Dowdney, 2000; Tyrka et al. 2008; Worden, 1996). Having a parent die before a child turns 18 years old is also associated with early mortality (Li et al., 2014). Compounding their bereavement, families often experience other major stressors: diminished financial resources, a change in residence, additional responsibilities within the home, and changes in parent-child relationship dynamics (see 
Wolchik et al., 2008). Widowed parents face having to help their children adapt to a major loss while simultaneously adjusting to their new role as single parent and coping with their own grief (Yopp \& Rosenstein, 2012). Taken together, parentally bereaved families face multiple challenges to intrafamilial relationships and overall family functioning.

In households where there had been two parents, the surviving parent's psychological well-being and ability to effectively carry out parental responsibilities are integral to fostering healthy family adaptation. The quality of the surviving parent-child relationship and the parent's ability to provide a structured and consistent home environment are strong predictors of children's coping and psychosocial functioning (Haine et al., 2006; Luecken et al., 2009; Kwok et al., 2005). Specifically, several lines of evidence have established a robust relationship between a bereaved child's psychological health and a child-centered parenting approach, which includes provision of emotional warmth (e.g., acceptance, praise, empathy) and consistent structure and discipline. These parenting styles are associated with less depression and anxiety, greater psychological resiliency in parentally bereaved children (Lin et al., 2004; Haine et al. 2006; Raveis et al., 1999), and positive perceptions of parents by their children (Saldinger, Porterfield \& Cain, 2004). A childcentered parenting approach is also predictive of fewer psychological problems in children one year following the death of a parent (Kwok et al. 2005), as the combination of parental warmth and effective discipline is believed to foster resiliency and coping competencies. These findings underscore the vital role that surviving parents play in shaping their family's adjustment following parental death.

When the father is the surviving parent, children may be at particularly heightened risk for poor coping and adaptation. The limited research on parental gender differences following spousal death suggests that widowed fathers are less likely to adopt a child-centered parenting approach than widowed mothers (Boerner \& Silverman, 2001; Saldinger et al., 2004). Bereaved fathers tend to be less emotionally available to their children than bereaved mothers, and children in father-led homes experience less stability and more disruptions in their daily lives (Boerner \& Silverman, 2001). Saldinger and colleagues (2004) found that, compared to widowed mothers, widowed fathers are significantly less likely to communicate with their children about emotions, be attuned-and responsive-to their children's loss-related needs, facilitate a continued emotional bond between their children and the deceased parent, and engage children in meaning-making exercises. Gender differences in parenting approaches may, in part, account for the find- ing that children whose mothers died have lower self-esteem and poorer self-confidence than children whose fathers have passed away (Saler \& Skolnick, 1992). These data suggest that interventions for bereaved families should certainly be developed with attention to the gender of the surviving parent.

Research findings also support the widely held clinical observation that grieving men are less comfortable than women in seeking and receiving support from others. Saldinger and colleagues (2004) found this same pattern of gender differences in widowed parents. Specifically, widowed fathers are less likely to solicit support networks or connect their children with either formal (e.g., therapeutic) or informal (e.g., having them talk with family members) support. They also noted that fathers tend to perceive asking for or receiving help as a sign of weakness, which ultimately could limit the support they and their children receive. By restricting assistance from outside sources, widowed fathers may foster a dynamic in which they and their children grieve in isolation. Given these findings, father-led homes appear to represent a particularly vulnerable subset of bereaved families.

The degree to which a widowed father is able to function optimally as his family's sole caregiver and fulfill his parental responsibilities may be compromised by his own psychological well-being following the death of his wife or partner. Under any circumstances, psychological distress is to be expected immediately following such a loss. However, given the considerable burden of parental responsibilities in a time of grief, the distress of widowed fathers may be particularly intense. Despite the importance of addressing the psychological needs of these men, the psychological functioning of widowed fathers with children in the home has never been the focus of empirical study. These bereaved families have been largely overlooked and warrant careful investigation to inform interventions to meet their needs.

In the United States alone, an estimated 100,000 children currently live with widowed fathers (Heron, 2012; United States Census Bureau, 2009). The few clinical interventions involving widowed parents and their children are not specific to the gender of the parent. For example, Sandler and colleagues (2003) and Haine and coworkers (2006) reported on a clinical intervention designed to improve bereaved children's psychological functioning by focusing on both the child and the surviving parent. The intervention was associated with positive changes in family dynamics and adaptation among both children and surviving parent. However, the generalizability of this promising research to widowed fathers is limited because the intervention focused more on child adjustment than parental coping, and only $21 \%$ of participating families represented father-led homes. 
Despite the clear supportive needs of these families, widowed fathers remain very much an overlooked and underserved population. To develop and implement targeted interventions for widowed fathers and their children, it is first necessary to better understand these men, their experiences, and the specific challenges they face.

\section{METHODS}

The present study examined the experiences and psychological functioning of widowed fathers with dependent-age children at home. We here describe the development of an online survey to study a subset of this population: fathers of children whose mother died from cancer. The decision to survey only fathers widowed due to cancer death was made, in part, because cancer is by far the single leading cause of widowed father-led families in the United States. Our survey was designed to probe pertinent aspects of widowed fatherhood to inform the development of a clinical intervention. Survey items included both standardized measures and questions specifically developed for use in the study.

The study was approved by our university's institutional review board. The online survey was housed on an open website created and maintained by the Single Fathers Due to Cancer program (www.single fathersduetocancer.org). In addition to hosting the survey, this website serves as a resource for widowed fathers. Fathers in our study visiting the website had the option of completing the survey, but access to the resources available on the site was not contingent on doing so. Information about the website was circulated among colleagues at other cancer centers by reaching out to members of relevant organizations (e.g., hospice and bereavement programs, the American Psychosocial Oncology Society), and by word of mouth. In addition, such national media outlets as The New York Times (Brody, 2013), the Today Show (National Broadcasting Company, 2013), and the Associated Press (Waggoner, 2013) reported on the Single Fathers Due to Cancer program and included mention of the website.

\section{Participants}

Participants completing the survey were self-identified as widowed fathers. Fathers visiting the website had the option of participating in the study by clicking on a button labeled "Take the Survey," which directed them to an informed consent statement. After completing the survey, fathers were asked if they were interested in filling out a follow-up survey in six months, and willing participants provided their contact information. The data presented in this manu- script are only baseline responses for fathers completing the survey between October of 2012 and November of 2013.

The eligibility criteria included: (1) being a male aged 18 years or older and (2) having at least one biological or adopted dependent-age child currently living in the home whose mother died from cancer. Both the informed consent and survey were written in English.

\section{Materials}

The survey was designed in modular form to allow for flexibility so that new modules can be substituted to assess different domains of interest over time. Surveys of similar construction have been employed elsewhere in the literature (e.g., Long et al., 2012). Our survey consisted of three modules. All subjects completed module 1 and were then randomly assigned to complete module 2 or 3 . After completing the two assigned modules, subjects were given the option of completing the remaining module or ending the survey.

\section{Module 1}

Module 1 queried father and family demographics; current living situation; the child's mother's illness and death history; and communication with oncologists during the mother's illness. This module also included the Kansas Parenting Satisfaction Scale (KPSS) (James, 1985), a three-item Likert-type measure assessing parent satisfaction with their child's behavior, their parenting, and their relationship with their child. The Cronbach's alpha score of reliability was found to be 0.84 (James, 1985). Module 1 also included the Psychological Adaptation Scale (PAS) (Biesecker et al., 2013), a 15-item Likert-type scale assessing psychological adaptation. For the purposes of our study, the PAS stem question was modified to read as follows: "Thinking about your parenting in the time since [the mother]'s death..." Cronbach's alpha scores for the PAS have ranged from 0.83 to 0.97 (Biesecker et al., 2013). Finally, this module included 12 Likert-type questions assessing self-perceived parental competence. These items were specifically created for our study, as no validated measures of widowed parenting had been published previously. Items addressed fathers' perceived level of parenting stress, their ability to provide empathy and discipline for their children, and the degree to which they felt they were meeting their own parenting expectations.

\section{Module 2}

The second module assessed fathers' current depressive symptomatology using the Center for 
Epidemiologic Studies Depression Scale (CES-D) (Radloff, 1977). The CES-D is a 20-item Likerttype measure in which respondents rate the frequency with which they experienced each item over the preceding seven days. Responses for each item range from 0 (rarely) to 3 (most or all the time). The CES-D yields an overall score ranging from 0 to 60 , with higher scores indicating greater depression. A cutoff score of 16 is commonly utilized to identify people with clinically significant depressive symptoms. Metaanalyses have supported a four-factor structure of the CES-D with the following subscales: "somatic activity," "depression," "positive affect," and "interpersonal problems" (Shafer, 2006).

\section{Module 3}

The third module assessed a father's grief with the Texas Inventory of Grief-Revised (TRIG) (Faschingbauer et al., 1977), which is a 21-item Likert-type scale where participants rate how true each item is for them on a scale from 1 to 5 . The TRIG is divided into two sections: part A, which consists of 8 items, and part B, which consists of 13 items. The items in part A assess retrospective grief by asking the respondent to recall their grief immediately following the death and respond accordingly (e.g., "I found it hard to sleep after this person died"). Items in part $B$ ask the participant to rate their present feelings related to the death (e.g., "I still cry when I think of the person who died"). The TRIG has been found to have excellent internal consistency and reliability (Nam \& Eack, 2012).

\section{Data Collection and Management}

All data were collected online using Qualtrics software (Qualtrics LLC, Provo, Utah). Instances of partial completion in which subjects did not complete items about the specifics of their children's mother's death and at least one set of items about the end-oflife experience were not included in the dataset. Identifiers (name, phone number, address, email address) were collected only from respondents who agreed to complete the six-month follow-up survey; all other respondents remained anonymous.

\section{Data Analysis}

Descriptive statistics were compiled to characterize the sample of widowed fathers, including frequency distributions, means, ranges, and standard deviations as appropriate. Univariate and multivariate linear regression models were run to evaluate the association of fathers' and mothers' characteristics on scores. Based on the univariate model results and the consensus decision among the authors about which variables were clinically important to include, multivariate models for each score were run, including the covariates listed in Table 4.

\section{RESULTS}

A total of 308 fathers who met the eligibility criteria completed the survey. Given that a primary rationale for the survey was to inform interventions for relatively recently widowed fathers, data analysis was limited to fathers whose children's mother died within five years of when they completed the survey (the time between survey completion and death of mother ranged from 0 months to 19 years). This restriction eliminated 43 of the 308 eligible subjects. To create a more uniform sample, the six subjects who reported having not been married to their children's mother were eliminated from further analyses. Thus, a total of 259 respondents (84\% of those who completed the survey) were included in the data analysis, with each father married to his children's mother at the time of her death, which occurred within five years of completing the survey. Of these subjects, 197 (76\%) opted to complete all three modules. The average survey completion time was 33 minutes.

The data on father characteristics are presented in Table 1 . The majority of fathers completed the survey within a year of their wife's death. The ages of fathers ranged from 28 to 69 years (mean $(X)=$ $46.81, S D=7.54$ ) and were normally distributed. The majority of respondents were Caucasian, possessed a post-high school degree, were employed on a full-time basis, and earned at least $\$ 50,000$ a year. Respondents came from 10 different countries, with the vast majority from the United States $(95 \%)$. Fathers identified living in a total of 38 states, with North Carolina (16\%), California (10\%), and Texas, Virginia, and New York (7\% each) representing the most common states of residence.

The majority of fathers identified themselves as being the sole adult in their household responsible for caring for their children at the time they completed the survey (90\%) and not currently being in a romantic relationship (83\%). The length of the fathers' marriages to their wives ranged from 6 months to 32 years $(X=15.6$ years, $S D=6.84)$ at the time of a wife's death. The majority of fathers reported having one $(33 \%)$ or two $(46 \%)$ children under the age of 18 living in the home at the time of their wife's death. The ages of the children at the time the father completed the survey ranged from 7 months to 19 years. The gender of the children was evenly split, as $71 \%$ of the fathers reported having at least one son and $69 \%$ reported having at least one daughter. When asked to rate "the importance of religion in 
Table 1. Father and family characteristics

\begin{tabular}{|c|c|c|}
\hline Mean age in years (range) & & $47(28-69)$ \\
\hline Race: Caucasian & & $216 / 240(90 \%)$ \\
\hline \multicolumn{3}{|l|}{ Education } \\
\hline & $<$ College degree & $66(27 \%)$ \\
\hline & College degree & $88(36 \%)$ \\
\hline & Postgraduate degree & $92(37 \%)$ \\
\hline \multicolumn{3}{|l|}{ Employment status } \\
\hline & Full-time & $198(81 \%)$ \\
\hline & Not full-time & $47(19 \%)$ \\
\hline \multicolumn{3}{|l|}{ Income } \\
\hline & Less than $\$ 50,000 /$ year & $58(24 \%)$ \\
\hline & $\$ 50,000-100,000 /$ year & $79(32 \%)$ \\
\hline & Over $\$ 100,000 /$ year & $106(43 \%)$ \\
\hline \multicolumn{3}{|l|}{ Importance of religion } \\
\hline & Somewhat important & $76(31 \%)$ \\
\hline & Very important & $96(39 \%)$ \\
\hline & Not important at all & $76(31 \%)$ \\
\hline \multicolumn{3}{|l|}{ Number of children } \\
\hline & 1 & $86(33 \%)$ \\
\hline & 2 & $119(46 \%)$ \\
\hline & $3-5$ & $54(21 \%)$ \\
\hline Mean age of oldest child in years (range) & & $11(1-19)$ \\
\hline Mean age of youngest child in years (range) & & $8(0-19)$ \\
\hline \multicolumn{3}{|l|}{ Time from wife's death to survey } \\
\hline & $0-6$ months & $99(39 \%)$ \\
\hline & $6-12$ months & $45(18 \%)$ \\
\hline & $12-24$ months & $52(20 \%)$ \\
\hline & $24-60$ months & $60(23 \%)$ \\
\hline \multicolumn{3}{|l|}{ Current relationship status } \\
\hline & In a relationship & $46(19 \%)$ \\
\hline & Not in a relationship & $200(81 \%)$ \\
\hline \multicolumn{3}{|l|}{ Current sole caregiver } \\
\hline & Sole caregiver & $222(90 \%)$ \\
\hline & Shared caregiving & $26(10 \%)$ \\
\hline \multirow[t]{3}{*}{ Mental health utilization since wife's death } & & \\
\hline & Psychologist & $(28 \%)$ \\
\hline & Psychiatrist & $(8 \%)$ \\
\hline
\end{tabular}

shaping their daily lives," fathers were relatively evenly divided between describing religion as "very important," "somewhat important," or "not important at all." Approximately one quarter of fathers reported accessing the services of a psychologist since their wife's death (28\%), and even fewer reported having met with a psychiatrist (8\%).

The characteristics of subjects' wives are presented in Table 2. They ranged in age from 25 to 69 years $(X=41.1, S D=7.29)$ at the time of their initial cancer diagnosis. The mean length of time between diagnosis and death was three years. The most frequently reported diagnoses were breast (37\%), gastrointestinal (14\%), and gynecological (9\%) cancers. No other single diagnosis was reported by more than 5\% of fathers. With regard to cancer staging, nearly half of fathers reported that their wives were found to have stage 4 cancer at the time of initial diagnosis.

\section{Fathers' Psychological and Parental Functioning}

The results for measures assessing fathers' psychological functioning are presented in Table 3. The mean score on the CES-D was 22.6, which is considerably higher than the commonly accepted threshold score of 16 used to identify persons with clinically significant depressive symptoms. Notably, $65 \%$ of fathers in this sample had scores of 16 or greater on this measure. TRIG total score ranged from 31 to 103, with a mean of 70.3. Subcores for TRIG part B, which measures current grief symptomatology, ranged between 15 and 65 , with a mean of 46.1 . Mean PAS total score ranged from 1.0 to 4.9 , with a mean of 3.2.

The results for parenting variables are also given in Table 3. The mean KPSS score of 15.8 indicates that fathers had relatively highly satisfied with their 
Table 2. Wives' pre-death characteristics

\begin{tabular}{llr}
\hline \hline $\begin{array}{l}\text { Mean age in years at } \\
\text { diagnosis (range) }\end{array}$ & \\
\hline $\begin{array}{l}\text { Time from diagnosis to } \\
\text { death }\end{array}$ & & \\
& & \\
& & \\
& $6-6$ months & $37(14 \%)$ \\
& $12-24$ months & $29(11 \%)$ \\
& 2 years or & $69(27 \%)$ \\
greater & $123(48 \%)$ \\
Cancer diagnosis & Breast & $95(37 \%)$ \\
& GI & $37(14 \%)$ \\
& Gynecologic & $23(9 \%)$ \\
& Brain & $14(5 \%)$ \\
& Remaining & $89(34 \%)$ \\
types & \\
Stage of cancer at & & \\
diagnosis & Stage 1 & $22(10 \%)$ \\
& Stage 2 & $37(16 \%)$ \\
& Stage 3 & $60(27 \%)$ \\
& Stage 4 & $106(47 \%)$ \\
CNS involvement & & $104(44 \%)$ \\
& Yes & $133(56 \%)$ \\
& No & \\
\hline \hline
\end{tabular}

parenting. Specifically, only $8 \%$ of fathers reported being dissatisfied ("extremely," "very," "somewhat") with their child's behavior and with their relationship. Only $18 \%$ of fathers reported being dissatisfied with themselves as parents.

Fathers' responses on the 12 Likert-type questions created for this study to assess self-perceived paren- tal competence indicated that most fathers perceived themselves as meeting their own parental expectations. At the same time, the majority of fathers reported that meeting the responsibilities of sole parenting was highly stressful. The responses to two of the questions illustrate these findings and are given in Table 3. Specifically, 83\% of fathers agreed (mildly, moderately, or strongly) with the statement "I am doing an excellent job raising my child since [the child's mother] died," and $75 \%$ of fathers agreed with the statement "I feel overwhelmed by the responsibilities of being a parent." The remaining items assessing whether fathers viewed themselves as meeting their own expectations and regarding parenting stress levels yielded similar results.

\section{Multivariate Analyses}

Multivariate models to evaluate the association of covariates of interest with CES-D and PAS scores are presented in Table 4. For the CES-D, father's age at the time of the survey was the only variable that had a significant association with depression. On average, for each 10-year increase in age, a father's CES-D score dropped 5.9 points $(p<0.01)$. For the PAS, currently being in a relationship $(p=0.02)$ and feeling that religious faith is very important $(p=0.0003)$ or somewhat important $(p=0.05)$ in shaping daily life were associated with increased PAS scores. Those who felt religion was very important in their daily lives had PAS scores that were half a point higher than those who felt religion was not important. For each increased year of an eldest

Table 3. Psychological and parenting measures

\begin{tabular}{|c|c|c|c|}
\hline \multirow[b]{2}{*}{ Scale } & \multirow[b]{2}{*}{ Details } & \multicolumn{2}{|c|}{ Entire Group } \\
\hline & & $\overline{\operatorname{Mean}(X)}$ & $\overline{S D}$ \\
\hline CES-D total score & $\begin{array}{l}\text { Sum of } 20 \text { items, range }=0-60 \\
\text { higher }=\text { greater depression }\end{array}$ & 22.6 & 12.37 \\
\hline TRIG total score & $\begin{array}{l}21 \text { items, range }=21-105 \\
\text { higher }=\text { more grief }\end{array}$ & 70.3 & 12.89 \\
\hline TRIG part B score & $\begin{array}{l}13 \text { items, range }=13-65 \\
\text { higher }=\text { more grief }\end{array}$ & 46.1 & 9.35 \\
\hline PAS total mean score & $\begin{array}{l}15 \text { items, range }=1-5 ; \\
\text { higher = better adaptation }\end{array}$ & 3.2 & 0.86 \\
\hline KPSS & $\begin{array}{l}3 \text { items, range }=3-21 \\
\quad \text { higher }=\text { more parental satisfaction }\end{array}$ & 15.8 & 3.38 \\
\hline Parenting item-Expectations & $\begin{array}{l}\text { Excellent job raising child } \\
1=\text { strong disagree, } 6=\text { strong agree }\end{array}$ & 4.4 & 1.16 \\
\hline Parenting item-Stress & $\begin{array}{l}\text { Overwhelmed by being a parent } \\
1=\text { strong disagree, } 6=\text { strong agree }\end{array}$ & 4.3 & 1.46 \\
\hline
\end{tabular}

CES-D = Center for Epidemiologic Studies Depression Scale; TRIG = Texas Inventory of Grief-Revised; KPSS = Kansas Parenting Satisfaction Scale; Parenting Item-Expectation = "I am doing an excellent job raising my child since [the child's mother] died"; Parenting Item-Stress = "I feel overwhelmed by the responsibilities of being a parent"; PAS = Psychological Adaptation Scale. 
Table 4. Multivariate linear regression models

\begin{tabular}{|c|c|c|c|c|}
\hline & \multicolumn{2}{|c|}{ CES-D Total Score } & \multicolumn{2}{|c|}{ PAS Total Score } \\
\hline & Estimate & $\operatorname{Pr}>|t|$ & Estimate & $\operatorname{Pr}>|t|$ \\
\hline Intercept & 40.00 & $<.0001$ & 3.02 & $<.0001$ \\
\hline Father's age at survey & -0.589 & 0.0013 & 0.008 & 0.568 \\
\hline Years from death to survey completion & -0.045 & 0.9495 & -0.03 & 0.5508 \\
\hline Education: college graduate vs. less than college & -2.77 & 0.2098 & -0.13 & 0.3822 \\
\hline Education: postgraduate degree vs. less than college & -1.95 & 0.3712 & -0.12 & 0.4258 \\
\hline Importance of religion: somewhat vs. not at all & -2.48 & 0.2532 & $\mathbf{0 . 3 1}$ & 0.0462 \\
\hline Importance of religion: very vs. not at all & -2.51 & 0.2205 & 0.53 & 0.0003 \\
\hline Wife's age at diagnosis & 0.30 & 0.1199 & -0.001 & 0.9549 \\
\hline Wife's cancer stage 4 at diagnosis & 1.78 & 0.316 & -0.01 & 0.9681 \\
\hline Oldest child age at wife's death & 0.07 & 0.7667 & -0.04 & 0.0191 \\
\hline Help in preparing for single fatherhood & 0.40 & 0.8181 & 0.09 & 0.4754 \\
\hline Currently in a romantic relationship & -2.11 & 0.369 & 0.37 & 0.0239 \\
\hline
\end{tabular}

* "Unsure" responses counted as not stage 4.

CES-D = Center for Epidemiologic Studies Depression Scale; PAS = Psychological Adaptation Scale.

child's age, father's PAS score decreased by 0.04 points $(p=0.02)$. There were no significant associations between any of the variables and TRIG or KPSS scores.

The multivariate models did not yield significant associations for a number of variables, including the length of time between the wife's death and when subjects completed the survey, that is, there was no relationship between the amount of time fathers had been widowers and scores on the CES-D, TRIG, PAS, or KPSS.

\section{DISCUSSION}

In parentally bereaved families, the surviving parents' ability to cope and provide a stable home environment strongly predicts children's abilities to adapt and their psychosocial functioning. Widowed fathers and their families are at especially heightened risk for poor coping and maladaptive psychosocial outcomes, yet, to our knowledge, this exploratory study is the first of its kind to examine experiences, psychological functioning, and perceived parenting efficacy in this population. Overall, our findings suggest that, while widowed fathers perceive themselves as meeting their parental responsibilities, it comes at a considerable psychological cost as they experience substantial distress as well as high levels of stress related to their role as single parents.

The results found in this sample of 259 fathers whose wives had died from cancer within five years of participating in the study indicate that widowed fathers with dependent-age children experience distress across several domains of psychological functioning. Perhaps most striking was the proportion of fathers who reported clinically significant depressive symptomatology, as nearly two thirds of men scored above the threshold typically employed to screen for depression on the CES-D. This finding underscores concerns about the fathers' psychological well-being while also raising questions about the degree to which depression may impact parenting efficacy. A father's ability to meet the increased parenting demands of sole fatherhood and employ a child-centered parenting approach to facilitate his children's coping and adaptation may be compromised if he is clinically depressed. The results also suggest that many fathers experience intense grief with respect to both current symptoms and recall of the grief that immediately followed their wife's death. To put the results in context, the mean TRIG part B score for this sample, in which a higher score reflects more current grief symptoms, was greater than the mean scores reported in nearly all published studies reporting TRIG scores as a measure of grief (Nam \& Eack, 2012). Such studies included subjects who had lost a close family member within the prior year (Ringdal et al., 2001), and seniors only two months removed from a spouse's death (Thompson et al., 1991).

The fathers' psychological distress as noted in the CES-D and TRIG findings was mirrored by low adaptation scores as measured by the PAS. The mean total PAS score for our sample was lower than that for individuals adapting to being the primary caregiver for loved ones with such significant medical disabilities as Down syndrome (Truitt et al., 2012) and muscular dystrophy (B.B. Biesecker, personal communication, July 23, 2014; Peay et al., 2014). Further, the mean score for our sample was similar to that observed in subjects adapting to their own debilitating and life-altering illnesses, including 
Klinefelter syndrome (B.B. Biesecker, personal communication, July 23, 2014; Turriff et al., 2011) and Huntington's disease (B.B. Biesecker, personal communication, July 23, 2014). Taken together, the CES-D, TRIG, and PAS results underline the degree to which widowed fathers experience psychological distress and poor adaptation following the loss of a spouse. These findings are especially noteworthy considering that the length of time between a wife's death and participation in the study was not significantly related to distress levels.

It was not surprising to find that fathers reported feeling overwhelmed by the increased demands of sole parenthood. The vast majority of fathers reported being the lone primary caregiver for their children. Consequently, parenting responsibilities that were once shared with wives now fell solely to them. That these fathers felt overwhelmed and stressed in their efforts to meet the demands of sole fatherhood is consistent with the elevated levels of psychological distress we found. Interestingly, despite their symptom burden, the fathers perceived themselves as generally meeting their parental responsibilities and satisfying their own expectations as parents in the wake of their wife's death. One interpretation of these apparently divergent findings is that, whether by conscious choice or by necessity of circumstance, fathers prioritized their parenting and household responsibilities at the expense of their own psychological well-being. Following a spouse's death, widowed fathers are faced with three immediate and simultaneous challenges: shepherding their children through their grief, adjusting to the demands of being a sole parent and household manager, and attending to their own psychosocial health. It may be that many fathers devote their limited time and energy to the first two tasks while neglecting their own well-being. For some, placing the interests of their children above their own may be a conscious choice. However, our clinical experience in working with widowed fathers suggests that priorities are most often dictated by the immediate day-today demands of single parenthood.

Another explanation for the perception of effective parenting juxtaposed with very high levels of psychological distress is that fathers are not parenting as effectively as their self-reports would suggest. Unlike assessments of internal psychological functioning (e.g., symptoms of depression, anxiety, or grief) in which to a large extent self-perception is reality, parenting behaviors are intimately tied to interpersonal relationships. It is possible that fathers overestimate their parenting competence relative to what their children would report or to what behavioral observations of father-child interactions would reveal.
Multivariate analyses revealed surprisingly few statistically significant relationships. With respect to the CES-D, the lone significant association was between father's age and CES-D score, with younger fathers reporting more depressive symptoms. It may be that younger fathers married for a shorter period of time and with younger children experience more distress because of the small amount of time that their families were whole and due to the early loss of their idealized futures with their wives. In addition, raising young children unable to recall when their mothers were alive may be particularly painful for fathers who may, in turn, feel added pressure to maintain their wife's memory within the home. Fathers' psychological adaptation was positively correlated with being in a romantic relationship and valuing religion in their daily lives. It may be that a father who had reestablished a relationship was in a better position to do so because he had a healthier adaptation to his wife's death or, conversely, that being in a relationship facilitated his adaptation. The association between deep religious faith and better adaptation is consistent with a large body of literature that has noted a link between religious belief and more successful coping (Wortmann \& Park, 2008).

Notably, multivariate analyses did not yield a significant relationship between the length of time fathers had been widowed (ranging between 0 and 60 months) and levels of depression, grief, perceived parental efficacy, or psychological adaptation. This was surprising given the expectation that fathers further removed from their wife's death would have less distress than more recently bereaved fathers, and suggests that the timing and trajectory of bereavement may be different for individuals with dependent children compared with other forms of bereavement. The finding that fathers remain distressed years following a wife's death is consistent with the aforementioned conceptualization that these men defer their own well-being while focusing on their children and household management. This may also reflect a potential limitation of our study in that the fathers in this sample were self-selected and clearly highly distressed.

The findings from our study suggest several clinical implications. Bereaved parents with children at home may differ in important ways from bereaved persons without young children. Clinicians providing therapeutic services to widowed fathers with dependent-age children should perform careful assessments for depression, complicated grief, and stress uniquely linked with a father's role as his child's sole parent. Fathers who prioritize their children's and family's functioning to the detriment of their own psychological well-being may require more active clinical intervention. One avenue for reaching 
this population that has yielded preliminary success is an intervention via the support-group format (Yopp \& Rosenstein, 2013). Regardless of the content or form of any future intervention, the data from this study are consistent with findings that bereaved men are hesitant to access supportive resources. Despite the degree of their psychological distress, relatively few fathers in our sample reported receiving psychological or psychiatric care in the months and years following their wife's death. Mental health practitioners are challenged to consider ways to offer services in ways that are palatable for men, particularly for younger fathers who may be in greater distress. The timing of when support is offered may be important. For fathers whose wives die an anticipated death (e.g., from terminal illnesses), who require long-term medical or palliative care, healthcare professionals and hospice workers may serve to bridge the mental health gap.

There are several limitations to our study that should be considered when interpreting the results. Most importantly, it is not possible to determine whether this sample was representative of the broader widowed father population. It may be that respondents who sought out the Single Fathers Due to Cancer website and completed the survey represented a more distressed subset of widowed fathers and may not reflect the full range of bereavement reactions. This may explain the lack of a relationship between length of being a widower and level of psychological distress. The generalizability of our findings is also limited by the homogeneity of the sample as participants had above-average levels of education and income and had access to the internet. However, it could be argued that, if fathers with more resources present with high levels of distress, those with fewer means may be even more vulnerable. Also, all fathers in our study were widowed due to cancer deaths and may be different from fathers whose spouses died from other illnesses or suddenly. The literature on whether cause of death is predictive of family adaptation is mixed (with the notable exception of parental death by suicide), so that the findings of our study might be relevant to the overall widowed father population. Collecting data via an online survey carries other limitations since all these data are self-reported. The nature of obtaining data via a website also means that we could not confirm whether respondents met eligibility criteria, although it seems highly unlikely that respondents would falsely identify themselves as widowed fathers due to cancer. Finally, the data are one-time reports, which does not allow for examination of changes in individual fathers over time. Future data collection and reports need to address the longitudinal course of this cohort of fathers.
Several future directions for interventions and research efforts with this population of fathers emerge from our study. These preliminary findings might inform hypotheses about specific psychological functioning, parenting behaviors, and the bereavement trajectory of widowed fathers. Ideally, data on the psychological functioning of the children and their relationships with their fathers would be collected in a longitudinal fashion. Future studies should identify interventions-either for individuals or groupsthat address fathers' distress and enhance their parenting and household management abilities. In order to assess the parenting efficacy of this population, new measures will need to be developed as none currently exist that target widowed parenting. In addition, to further advance our understanding of fathers' experiences following the death of a wife, clinicians and researchers should incorporate a conceptual model to help describe fathers' coping skills and predict adaptive outcomes for them and their children. The dual-process model of coping and bereavement (Stroebe \& Schut, 1999) offers promise in this regard. Finally, the findings of this study may be helpful in informing interventions for families in which one parent has a terminal illness.

In conclusion, in this self-selected sample of widowed fathers with dependent-age children, fathers reported substantial psychological distress even years removed from the death of their spouse. Our findings make clear the need for additional research and for development of targeted interventions for these fathers and their families.

\section{ACKNOWLEDGMENTS}

The authors would like to thank the fathers who shared their experiences by participating in our study. This study was supported by the University Cancer Research Fund at the University of North Carolina at Chapel Hill.

\section{REFERENCES}

Biesecker, B.B., Erby, L., Woolford, S., et al. (2013). Development and validation of the Psychological Adaptation Scale (PAS): Use and six studies of adaptation to a health condition or risk. Patient Education and Counseling, 93, 248-254.

Boerner, K. \& Silverman, P.R. (2001). Gender-specific coping patterns in widowed parents with dependent children. Omega: Journal of Death and Dying, 43(3), 201-216.

Brody, J. (2013). A lifeline for widowed fathers. The New York Times, April 22, 2013. Available at http:// www.nytimes.com.

Cerel, J., Fristad, M.A., Verducci, J., et al. (2006). Childhood bereavement: Psychopathology in the two years post-parental death. Journal of the American Academy of Child and Adolescent Psychiatry, 45, 681-690. 
Dowdney, L. (2000). Childhood bereavement following parental death. Journal of Child Psychology and Psychiatry, 41, 819-830.

Faschingbauer, T.R., DeVaul, R.A. \& Zisook, S. (1977). Development of the Texas Inventory of Grief. The American Journal of Psychiatry, 134, 696-698. Available at http:// ajp.psychiatryonline.org/journal.aspx?journalid=13.

Haine, R.A., Wolchik, S.A., Sandler, I.N., et al. (2006). Positive parenting as a protective resource for parentally bereaved children. Death Studies, 30, 1-28.

Heron, M. (2012). Deaths: Leading causes for 2009. National vital statistics reports, Vol. 61, No. 7. Hyattsville, MD: National Center for Health Statistics. Available at http:// www.cdc.gov/nchs/data/nvsr/nvsr61/nvsr61_07.pdf.

James, D. (1985). Characteristics of the Kansas Parental Satisfaction Scale among two samples of married parents. Psychological Reports, 51, 163-169. Available at http://www.amsciepub.com/loi/pr0.

Li, J., Vestergaard, M., Cnattingius, S., et al. (2014). Mortality after parental death in childhood: A nationwide cohort study from three Nordic countries. PLoS Medicine, 11(7), e1001679.

Lin, K.K., Sandler, I.N., Ayers, T.S., et al. (2004). Resilience in parentally bereaved children and adolescents seeking preventive services. Journal of Clinical Child and Adolescent Psychology, 33, 673-683.

Long, M.D., Kappelman, M.D., Martin, C.F., et al. (2012). Development of an internet-based cohort of patients with inflammatory bowel diseases (CCFA Partners): Methodology and initial results. Inflammatory Bowel Diseases, 18, 2099-2106.

Luecken, L.J., Kraft, A., Appelhans, B.M., et al. (2009). Emotional and cardiovascular sensitization to daily stress following childhood parental loss. Developmental Psychology, 45, 296-302.

Kwok, O., Haine, R.A., Sandler, I.N., et al. (2005). Positive parenting as a mediator of the relations between parental psychological distress and mental health problems of parentally bereaved children. Journal of Clinical Child and Adolescent Psychology, 34, 260-271.

Nam, I. \& Eack, S.M. (2012). Confirmatory factor analysis and cross-cultural examination of the Texas Revised Inventory of Grief (TRIG). Families in Society, 93, 65-73.

National Broadcasting Company (2013). "A safe place": Group helps dads widowed by cancer. Broadcast March 25, 2013. Available at http://www.today.com.

Peay, H.L., Tibben, A., Fisher, T., et al. (2014). Expectations and experiences of investigators and parents involved in a clinical trial for Duchenne/Becker muscular dystrophy. Clinical Trials, 11, 77-85.

Raveis, V.H., Siegel, K. \& Karus, D. (1999). Children's psychological distress following the death of a parent. Journal of Youth and Adolescence, 28, 165-180.

Radloff, L.S. (1977). The CES-D scale: A self-report depression scale for research in the general population. Applied Psychological Measurement, 1, 385-401.

Ringdal, G.I., Jordhoy, M.S., Ringdal, K., et al. (2001). The first year of grief and bereavement in close family members to individuals who have died of cancer. Palliative
Medicine, 15, 91-105. Available at http://pmj.sage pub.com.

Saldinger, A., Porterfield, K. \& Cain, A.C. (2004). Meeting the needs of parentally bereaved children: A framework for child-centered parenting. Psychiatry: Interpersonal and Biological Processes, 67, 331-352.

Saler, L. \& Skolnick, N. (1992). Childhood parental death and depression in adulthood: Roles of surviving parent and family environment. The American Journal of Orthopsychiatry, 62, 504-516.

Sandler, I.N., Ayers, T.S., Wolchik, S.A., et al. (2003). The Family Bereavement Program: Efficacy evaluation of a theory-based prevention program for parentally bereaved children and adolescents. Journal of Consulting and Clinical Psychology, 71, 587-600.

Shafer, A.B. (2006). Meta-analysis of the factor structures of four depression questionnaires: Beck, CES-D, Hamilton, and Zung. Journal of Clinical Psychology, 62, $123-146$.

Stroebe, M. \& Schut, H. (1999). The dual process model of coping and bereavement: Rationale and description. Death Studies, 23, 197-224.

Thompson, L.W., Gallagher-Thompson, D., Futterman, A., et al. (1991). The effects of late-life spousal bereavement over a 30-month interval. Psychology and Aging, 6, 434-441.

Truitt, M., Biesecker, B., Capone, G., et al. (2012). The role of hope in adaptation to uncertainty: The experience of caregivers of children with Down syndrome. Patient Education and Counseling, 87, 233-238.

Turriff, A., Levy, H.P. \& Biesecker, B. (2011). Prevalence and psychosocial correlates of depressive symptoms among adolescents and adults with Klinefelter syndrome. Genetics in Medicine, 13, 966-972.

Tyrka, A., Wier, L., Price, L.H., et al. (2008). Childhood parental loss and adult hypothalamic-pituitary-adrenal function. Biological Psychiatry, 63, 1147-1154.

United States Census Bureau (2009). Current population report, July 2009. Available at http://www.census.gov/ newsroom/releases/archives/population/cb10-81. html.

Waggoner, M. (2013). Dads whose wives died of cancer turn to NC group. Associated Press, June 15, 2013. Available at http://bigstory.ap.org.

Wolchik, S.A., Ma, Y., Tein, J.Y., et al. (2008). Parentally bereaved children's grief: Self-system beliefs as mediators of the relations between grief and stressors and caregiver-child relationship quality. Death Studies, 32(7), $597-620$.

Worden, J.W. (1996). Children and grief: When a parent dies. New York: Guilford.

Wortmann, J.H. \& Park, C.L. (2008). Religion and spirituality in adjustment following bereavement: An integrative review. Death Studies, 32, 703-736.

Yopp, J.M. \& Rosenstein, D.L. (2012). Single fatherhood due to cancer. Psycho-Oncology, 21, 1362-1366.

Yopp, J.M. \& Rosenstein, D.L. (2013). A support group for fathers whose wives died from cancer. Clinical Journal of Oncology Nursing, 17, 169-173. 